\title{
As ENSO Changes, So Change
the World's Watersheds
}

Adapted from "Possible Increased

Frequency of ENSO-Related Dry and Wet Conditions over Some Major

Watersheds in a Warming Climate," by Qiaohong Sun (Beijing Normal University), Chiyuan Miao, Amir AghaKouchak, Iman Mallakpour, Duoying Ji, and Qingyun Duan. Published online in BAMS, April 2020. For the full, citable article, see DOI:10.1175/BAMS-D-18-0258.1.

ecord-breaking drought and flood events around the world can be linked directly to the natural fluctuation of tropical Pacific sea surface temperatures known as the El NiñoSouthern Oscillation (ENSO). Many climate models project that the influence of ENSO in driving extremes will increase, along with the number of these extremes overall, in the twenty-first century.

Studies have also suggested that the teleconnection mechanisms that underlie ENSO and its associated impact on North America will intensify and/or shift position as a result of climate anomalies in a warmer climate. In fact, global warming might have already increased the likelihood of extreme events through changes in ENSO. ENSO-driven precipitation variability in the equatorial Pacific is projected to intensify in response to global warming, and this tends to increase ENSO-driven precipitation variability around the world. In addition, El Niño-driven precipitation anomalies in the equatorial Pacific are projected to move east, inducing an eastward shift in the Pacific-North American (PNA) teleconnection pattern. Intensification of El Niño-driven drying over the western Pacific Ocean is also predicted under global warming. Tropical cyclones are predicted to be more frequent during future El Niño events. Intense drought and excessive flooding in California are also projected. Recent studies have suggested a $\sim 12 \%$ increase in the spatial extent of ENSO teleconnections for precipitation. 
Changes in composite La Niña (8 MMM)

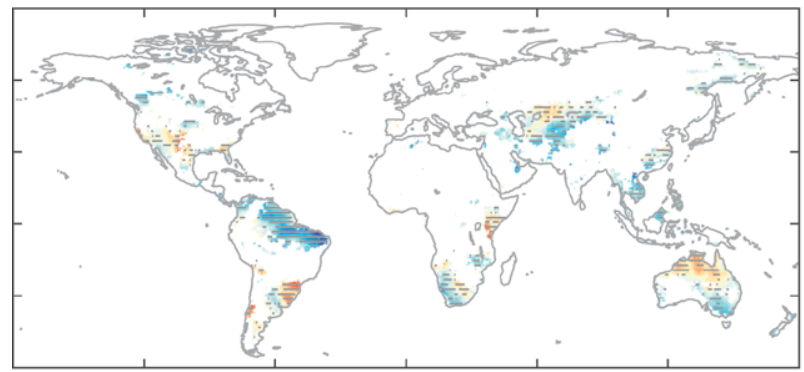

Changes in composite El Niño (8 MMM)

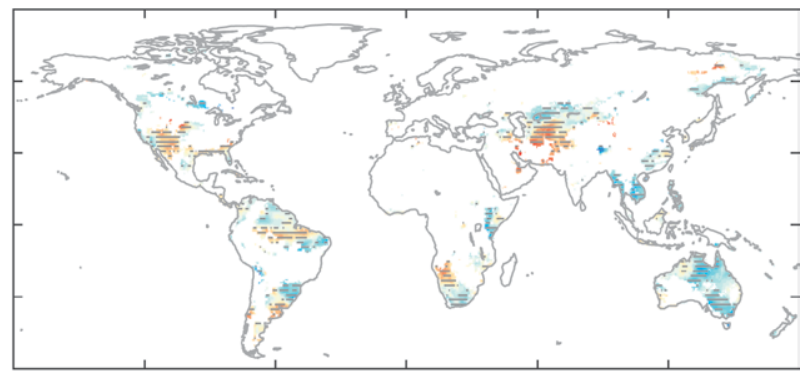

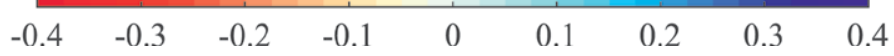

$\Delta$

* Changes in the composite of the annual SPI values in response to strong ENSO events for the RCP4.5 simulations (2006-60) relative to the historical simulations (1951-2005) as shown in the MMM of the 8 selected models. Stippling indicates regions where the sign of the MMM change is the same as the sign in at least twothirds of the models used.

We use global climate models to estimate future changes in ENSO-related precipitation teleconnection patterns at both the local and the river-basin scale, and we quantify changes in the frequency of ENSO-related extreme precipitation events in major river basins worldwide.

\section{Methods}

We used monthly precipitation for 1951-2005 (gridded to $0.5^{\circ}$ resolution) to calculate the standardized precipitation index (SPI), which is widely used to characterize dry/wet events. Because the SPI is normalized and dimensionless, it is particularly suited for characterizing the relative conditions across time periods and regions. We looked at long-term average 3-month precipitation totals and screened out amounts below $30 \mathrm{~mm}$.

With the Oceanic Niño Index (ONI; 3-month running mean of SST anomalies in the Niño-3.4 region), we determined whether El Niño or La Niña conditions were present. The ONI calculations remove the overall warming trend to more accurately reflect interannual ENSO variability.

We calculated a three-month SPI time series based on statistically downscaled precipitation simulations from 26 CMIP5 Earth system models $\left(0.5^{\circ} \times 0.5^{\circ}\right.$ grid resolution). Each simulation spanned 1951-2060. For 19512005, we used estimates of historical climate forcings. For 2006 onward, we used forcings corresponding to RCP4.5, a relatively moderate buildup of greenhouse gases.

We examined changes in precipitation patterns at the river-basin scale by choosing 117 river basins where models performed sufficiently well.2

Because our study mainly focused on the influence of ENSO on dry/wet conditions over global land, we selected the eight models that best captured the observed SPI response pattern to La Niña and El Niño phases at both the local grid cell scale and the river-basin scale.

To investigate potential changes in the occurrence of ENSO-related extreme precipitation, we calculated the difference in the frequency of severe dry/wet events (detrended SPI values for months exceeding 1.5 or -1.5 ) between the historical and projected periods. We also estimated the relative and absolute change in the average number of severe dry/wet events during the projected period.

\section{Results}

The anomalous precipitation patterns simulated in response to ENSO (for past years) were generally consistent with those reported in previous studies, with drier patterns over southwestern North America, southern China, and central Asia during La Niña phases but wetter

\footnotetext{
We used the standard hydrological year (October-September) to calculate the time series of the annual SPI value. ENSO years then refer to the subsequent hydrological year, so ENSO year 1998 refers to the year starting October 1998. For each model, the standard deviation ( $\sigma$ ) of ONI for December-February (DJF), when ENSO events typically peak, was used to classify years as neutral $(-0.5 \sigma<\mathrm{ONI}<0.5 \sigma)$, normal La Niña $(-1.0 \sigma<\mathrm{ONI}<-0.5 \sigma)$, strong La Niña $(\mathrm{ONI}<-1.0 \sigma)$, normal El Niño $(0.5 \sigma<\mathrm{ONI}<$ $1.0 \sigma)$, or strong El Niño $(\mathrm{ONI}>1.0 \sigma)$

At a threshold of $2.0 \sigma$ we found $17.07 \%$ and $64.29 \%$ increases, respectively, in the frequency of strong El Niño and strong La Niña events. These increases are not robust, but previous studies also have predicted an increased frequency of extreme ENSO events.

To investigate precipitation response, we computed the detrended annual SPI average for each grid location over all of the strong La Niña and strong El Niño years during 1951-2005 and 2006-60 to obtain composite patterns for each set of events. Using the composites, we identified changes in ENSO-related precipitation variability between the two periods

We looked for sufficient agreement with significant correlations between regional average annual detrended SPI and the ENSO index (observed for 1951-2005). Regional SPI composites for these 117 river basins during the strong La Niña and strong El Niño years were calculated for the observations and for all models for the 1951-2005 and 2006-60 periods to compare the changes in regional precipitation variability forced by the future ENSO events.
} 
patterns over northeastern South America, Australia, and southern Africa during La Niña phases. The multimodel mean (MMM) of the 26 models and of the 8 selected models captured the observed teleconnection patterns. The multimodel ensemble embraces distinctly different physical parameterizations.

Overall, the geographical area with a significant relationship between the ENSO index and SPI values under the RCP4.5 scenario broadly resembled what we found for the observed data and simulated historical periods. According to the MMM of the 26 models, the relationship between the ENSO index values and SPI value will increase in the future in many regions where precipitation variability already has been connected to ENSO variation. However, the MMM of the 8 selected models did not show this consistent strengthening in some of these regions. The consistent strengthening can be found across both the 26 models and the 8-model subset only in northern Australia and parts of central Asia.

Under our scenario, some regions of southern North America, southern South America, and southern central Asia were predicted to experience drier conditions during La Niña phases, while wetter conditions were predicted for Southeast Asia and Australia. Two-thirds or more of the models agreed as to the signs of these changes. However, there was little obvious strengthening of anomalous precipitation during El Niño phases, except in southern central Asia and northern Australia.

ENSO-driven precipitation variability was projected to increase slightly in river basins over southwestern North America, the Murray River basin, and the Aral basin. However, these MMMs showed different change signals for precipitation variability in the river basins of South America. The predicted future precipitation response to La Niña and El Niño was asymmetric. Under the RCP4.5 scenario, a "dry to drier, wet to wetter" pattern during La Niña phases was projected in some river basins, including the river basins of southern North America, central Asia, Southeast Asia, and Australia. In some basins, however, such as the Amazon River, the MMM of the 26 models was inconsistent with the MMM of the 8 selected models. During future El Niño phases, the "dry to drier, wet to wetter" pattern was not seen over most river basins. To the contrary, the historical negative precipitation anomalies over the Amazon River and Mekong River basins and the positive anomalies over the river basins of northern North America were projected to be ameliorated. Generally speaking, there are large uncertainties in the changes of precipitation anomalies during future El Niño phases, with large inconsistences evident between the MMMs of the 26 models and the 8 selected models.

Assessment of the 117 basins revealed large geographical differences in the projected changes in the frequency of severe dry and wet events. Under RCP4.5, according to both the MMMs of the 26 models and the 8 selected models, 45 rivers under El Niño conditions and 39 river basins under La Niña conditions were predicted to experience an increase in the frequency of severe dry events, while 44 under El Niño conditions and 44 under La Niña conditions would experience a decrease. Conversely, 59 river basins under El Niño conditions and 61 under La Niña conditions were predicted to have an increase in the frequency of severe wet events-a likely increase in the risk of floods-while a decreasing tendency was found for 21 river basins under El Niño conditions and 17 under La Niña conditions. Both intense dry events and excessive flooding were projected to increase in frequency in 22 river basins during La Niña phases, including the Aral River basin, the Colorado River basin, and the southern river basins of North Ameri$\mathrm{ca}$, indicating that these rivers may experience concurrent dry condition and wet condition in different parts of their basins during ENSO events. Some basins, such as the Mekong River basin, the Murray River basin, and river basins in Canada, were predicted to experience an increase in the frequency of severe wet events

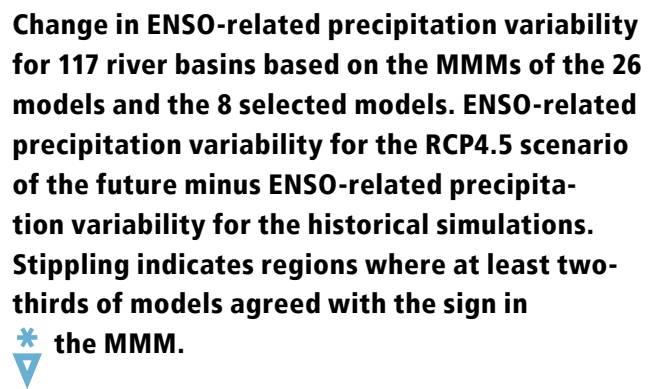

La Niña

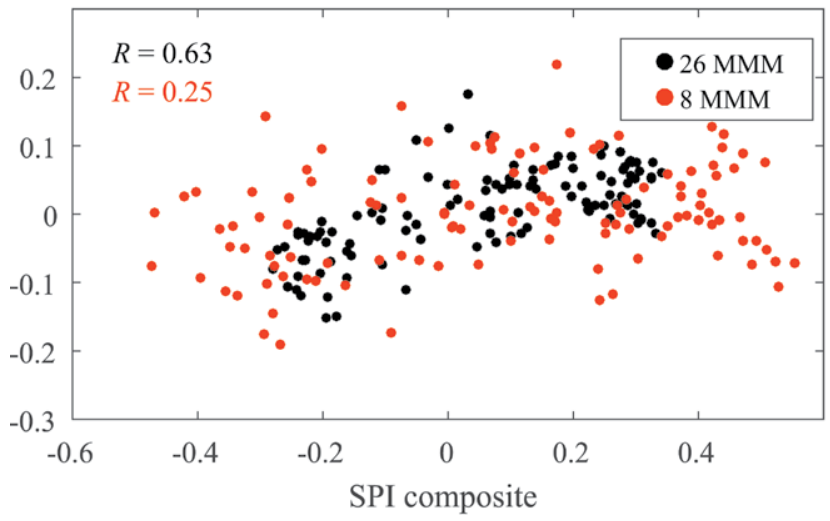

El Niño

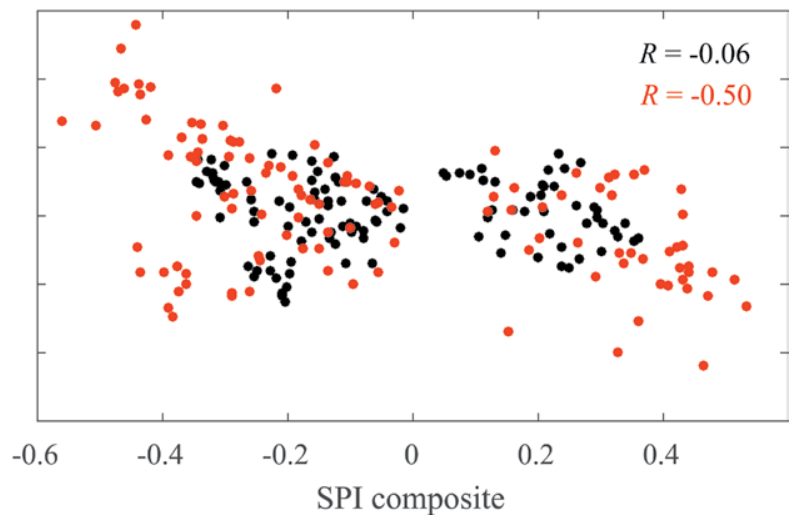


La Niña

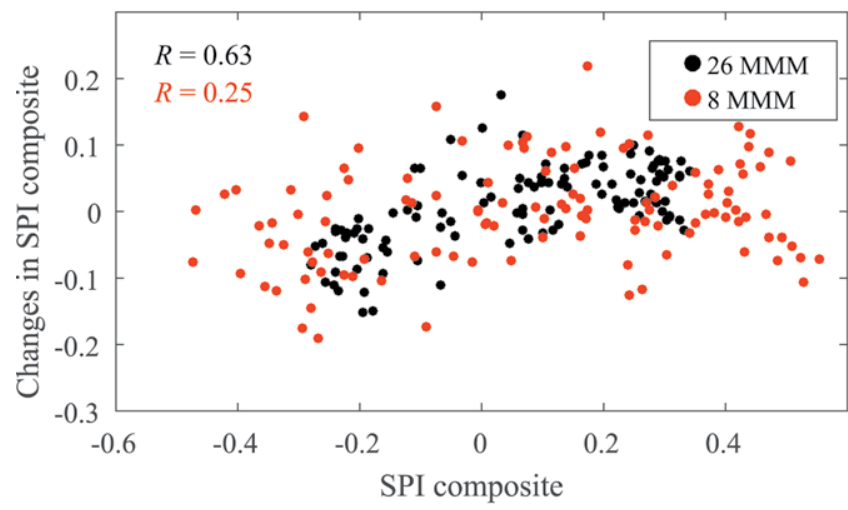

El Niño

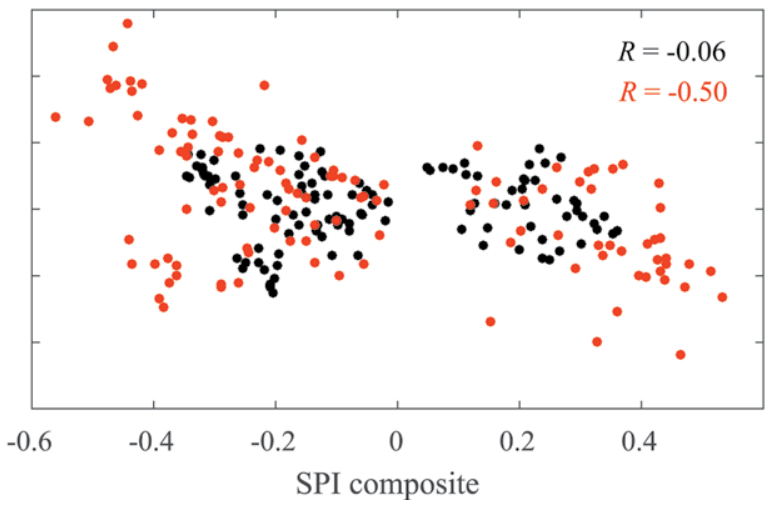

The relationship between the historical regional SPI composite and projected changes in the regional SPI composite over 117 major river basins, for strong La Niña and EI Niño phases, respectively. The black and red dots indicate the

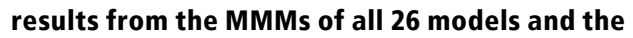
8 selected models, respectively.

but a decrease in the frequency of dry events during La Niña phases. Most river basins showed a broad increase in the frequency of severe wet events during El Niño phases. The Murray River basin and the Mekong River basin showed more pronounced and robust changes, with agreement from more than twothirds of the models. The river basins with large negative anomalous precipitation are predicted to experience an increase in severe dry events during La Niña.

However, a decrease in the total number of dry/wet events in a full year and a reduction in anomalous precipitation do not necessarily indicate a weakening of dry or wet events. For instance, in the Amazon River basin, where drought and below-average streamflow are commonly associated with El Niño, dry events did not decrease from October to December, when the teleconnection with ENSO is much stronger. Moreover, with an increased occurrence of extreme ENSO events, more areas were predicted to be subject to a greater frequency of dry events and floods. For instance, with an ENSO-index threshold of two standard deviations, the risk of dry events during El Niño phases and floods during La Niña phases was predicted to increase in the Amazon River basin. In the Colorado River basin, dry event was predicted to be more frequent and widespread under RCP4.5 in response to increasingly strong La Niña events.

\section{Discussion and conclusions}

Results of this study suggest that current teleconnections will strengthen in response to La Niña phases; simulations using 26 global climate models selected for good performance project that some regions with dry anomalies (e.g., southern North America, southern South America, and southern central Asia) will be drier, and those with wet anomalies (e.g., Southeast Asia and Australia) will be wetter. These are robust results that are not matched by predictions for El Niño phases. In fact, a slight weakening of annual precipitation anomalies for some regions (e.g., Southeast Asia and South America) is projected during El Niño phases. This asymmetric response of anomalous precipitation to each phase suggests that the influences of ENSO may change in the future, and that it cannot simply be assumed that all ENSO teleconnections will strengthen as suggested elsewhere. Because uncertainties remain, understanding the underlying mechanisms that drive these changes are an important avenue for future work.

In terms of selected river basins, most were predicted to experience an increase in the severity of both dry and wet events in response to future ENSO events. For example, ENSO-affected portions of Australia are projected to have extremely dry conditions, contributing to increased incidence of severe drought. Similarly, affected portions of central Asia, already a very dry region, could experience a worsening of conditions, with severe implications for the health and social stability of a population directly reliant on agriculture. Considering impacts such as these for major river basins and surrounding areas, it is essential to incorporate expected changes in ENSO teleconnections into account to improve seasonal or long-term drought and flood predictions. Moreover, in contrast to concurrent climate extremes-such as droughts and heat waves-that we currently see in response to ENSO, successive extreme events caused by projected shifts in ENSO would increase the temporal imbalance of water availability. This would pose new challenges for the management of freshwater resources and engineering facilities.

In summary, our study underscores some of the many implications of future changes in ENSO (and specifically El Niño and La Niña phases) patterns for natural hazards, and by extension disaster management. Thus, improving the accuracy of projections of changes in precipitation anomaly teleconnections should be the primary basis of future studies. $\therefore$ 